\title{
Severe tricuspid or mitral regurgitation in inoperable patients with aortic stenosis. Can we leave them alone?
}

\author{
Juan A. Crestanello, MD
}

From the Division of Cardiovascular Surgery, Mayo Clinic, Rochester, Minn.

Disclosures: Dr Crestanello serves on a medical advisory board and has received institutional research grants from Medtronic.

Received for publication Dec 8, 2017; accepted for publication Dec 18, 2017; available ahead of print Jan 26, 2018.

Address for reprints: Juan A. Crestanello, MD, Division of Cardiovascular Surgery, Mayo Clinic, 200 First St SW, Rochester, MN 55905 (E-mail: crestanello.juan@mayo.edu).

J Thorac Cardiovasc Surg 2018;155:2000-1

$0022-5223 / \$ 36.00$

Copyright (c) 2017 by The American Association for Thoracic Surgery

https://doi.org/10.1016/j.jtcvs.2017.12.068

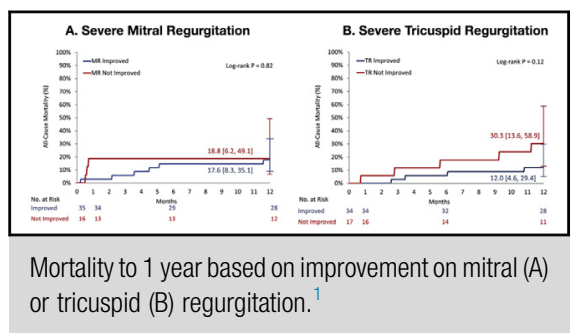

Central Message

Severe mitral or tricuspid regurgitation improves after TAVR. The impact of that improvement in outcomes is unknown.

See Article page 1991.
Mitral regurgitation (MR) and tricuspid regurgitation sis. ${ }^{2-4}$ They are a sign of more advanced cardiac diseases and associated with worse long-term prognosis. ${ }^{2-5}$ Regurgitation can be either functional, associated with ventricular remodeling, or organic. The severity of mitral regurgitation (MR) is determined by the magnitude of the valve lesion and the loading conditions of the ventricle. As such, relieving the aortic stenosis and decreasing the left ventricular systolic pressure would improve the MR. ${ }^{6}$ The effect of relieving the aortic stenosis on tricuspid regurgitation (TR) is less clear.

It is recommended that patients with severe MR and/or TR at the time of surgical aortic valve replacement undergo concomitant mitral and tricuspid surgery. ${ }^{7}$ The management of moderate MR and TR associated with aortic stenosis is less well established. ${ }^{6}$ Regardless of the severity, adding a surgical intervention to the mitral and/or the tricuspid valve increases the length of the procedure and the surgical morbidity and mortality. ${ }^{8}$ However, restoring the competency of those valves, once recovered from the initial surgical procedure, may be associated with better functional status despite their unclear effect on overall survival.

The incorporation of transcatheter aortic valve replacement (TAVR) to the armamentarium for the treatment of severe aortic stenosis challenges the recommendation of addressing associated severe MR or TR. On one hand, there is not a transcatheter device currently approved to treat MR and/or TR. On the other, many practitioners may feel that in inoperable or high-risk patients, addressing the aortic valve is just enough. Is it right to leave them alone? Many questions are pertinent to address this challenging problem: What is the fate of untreated severe MR and TR after TAVR? Does fixing or leaving alone severe MR or TR have any effect on the short- and long-term survival, symptoms, or quality of life? Can we identify the patients in whom the MR or TR will improve after TAVR? Do those patients will do better than those on whom the MR or TR will not improve?

In this issue of the Journal, Little and colleagues ${ }^{1}$ report the outcomes of TAVR in patients with severe MR or TR enrolled in the Expanded Use Study of the US CoreValve trial. This study provides an important contribution to our understanding of severe MR or TR associated with severe aortic stenosis. First, it established that TAVR in patients with aortic stenosis associated with severe MR or TR can be accomplished with similar procedural mortality and similar 1-year survival as in extreme risk patients without severe TR or MR. Second, it demonstrated that severe MR and TR improves at least one grade in $72 \%$ and $62 \%$ of patients at 1 year after TAVR. This improvement occurs early after the procedure and is maintained for up to a year. Third, it demonstrated that the improvement in MR or TR was not associated with improved survival. Finally, more than $50 \%$ of the patients improved their quality of life, as measured by health benefit analysis via the Kansas City Cardiomyopathy Questionnaire (KCCMQ).

However, this study has several limitations. First, the small number of patients, relatively short follow-up, and lack of comparison group may have prevented the authors from detecting potential changes in survival or quality of life associated with improvement in MR and/or TR. Second, the etiology of the MR and TR, degree of ventricular remodeling, and pulmonary artery pressures were not investigated. Discriminating between patients with organic or functional regurgitation and describing their outcomes after TAVR may help individualize and guide their treatment. In addition, the association between pulmonary hypertension, right ventricular function, and TR and their changes after 
TAVR were not investigated. Finally, the authors did not identify clinical, echocardiographic, or procedural characteristic associated with MR or TR improvement.

Despite these limitations, this study provides a fundamental insight into the outcomes of inoperable patients with severe TR and MR treated with TAVR: MR and TR improves in most patients and survival is similar. Larger studies will be required to confirm and refine those findings. The advent of transcatheter therapies for the mitral and tricuspid valve will allow us to address them if further studies demonstrate adverse effects on outcomes.

\section{References}

1. Little SH, Popma JJ, Klienman N, Deeb M, Gleasson T, Yakubov SJ, et al, Transcatheter aortic valve replacement in patients with severe mitral or tricuspid regurgitation at extreme risk for surgery. J Thorac Cardiovasc Surg. 2018;155:1991-9.

2. Barbanti M, Webb JG, Hahn RT, Feldman T, Boone RH, Smith CR, et al; Placement of Aortic Transcatheter Valve Trial Investigators. Impact of preoperative moderate/severe mitral regurgitation on 2-year outcome after transcatheter and surgical aortic valve replacement: insight from the Placement of Aortic Transcatheter Valve (PARTNER) Trial Cohort A. Circulation. 2013;128:2776-84.

3. Barbanti M, Binder RK, Dvir D, Tan J, Freeman M, Thompson CR, et al Prevalence and impact of preoperative moderate/severe tricuspid regurgitation on patients undergoing transcatheter aortic valve replacement. Catheter Cardiovasc Interv. 2015;85:677-84.

4. Nombela-Franco L, Eltchaninoff H, Zahn R, Testa L, Leon MB, Trillo-Nouche R, et al. Clinical impact and evolution of mitral regurgitation following transcatheter aortic valve replacement: a meta-analysis. Heart. 2015;101:1395-405. Erratum in: Heart. 2016;102:728.

5. Nath J, Foster E, Heidenreich PA. Impact of tricuspid regurgitation on long-term survival. J Am Coll Cardiol. 2004;43:405-9.

6. Wan CK, Suri RM, Li Z, Orszulak TA, Daly RC, Schaff HV, et al. Management of moderate functional mitral regurgitation at the time of aortic valve replacement: is concomitant mitral valve repair necessary? J Thorac Cardiovasc Surg. 2009;137: 635-40.e1.

7. Nishimura RA, Otto CM, Bonow RO, Carabello BA, Erwin JP III, Fleisher LA, et al. 2017 AHA/ACC Focused Update of the 2014 AHA/ACC Guideline for the Management of Patients with Valvular Heart Disease: a Report of the American College of Cardiology/American Heart Association Task Force on Clinical Practice Guidelines. Circulation. 2017;135:e1159-95.

8. Vassileva CM, Shabosky J, Boley T, Markwell S, Hazelrigg S. Tricuspid valve surgery: the past 10 years from the Nationwide Inpatient Sample (NIS) database. J Thorac Cardiovasc Surg. 2012;143:1043-9. 